\title{
Demand Analysis and Planning Research on the Construction of Multimodal Transport Center in LD
}

\author{
Shijun Yuan \\ Hunan Vocational College of Modern Logistics \\ Changsha, Hunan, China 410131
}

\author{
Jianhua Chen* \\ Hunan Vocational College of Modern Logistics \\ Changsha, Hunan, China 410131 \\ *Corresponding Author
}

\begin{abstract}
Based on the analysis of logistics demand in LD City, this paper studies the positioning, construction content and operation management modes of multimodal transport center in order to promote the development of modern logistics industry and serve the local economy.
\end{abstract}

Keywords-multimodal transport center; demand analysis; planning

\section{INTRODUCTION}

Located in the geometric center of Hunan, LD City is a thoroughfare that is accessible to north and south and links up west and east. The Zhuzhou-Guiyang railway and ShanghaiKunming high-speed railway run across the east to west, and the Luoyang-Zhanjiang railway runs through the south to north. 40 special railway lines connect with the whole city's main factories and mines, forming a "Mi-shaped" railway network. The important measures to promote the development of the modern logistics industry in LD are how to give full play to its advantages in railway transportation and build a multimodal transport center.

\section{ANALYSIS ON THE DEMAND OF LAND-USE SCALE OF} VARIOUS LOGISTICS FUNCTIONS IN PROJECT CONSTRUCTION

\section{A. Analysis on the Demand of Storage Scale in the Logistics Center}

1) Demand of storage scale in steel trading enterprise

We have carried out a sample survey for 22 units from 80 steel trading enterprises. Only 17 enterprises have made a clear answer to the storage demand area in these 22 steel trading enterprises, and their total demand for storage area is $9,950 \mathrm{~m} 2$. Estimated by proportion, the total demand for storage of the 80 steel trading enterprises is $46,823 \mathrm{~m} 2$.

Assuming that this logistics center can seize 30\%-50\% of market share of 80 steel trading enterprises' storage requirements, its storage requirement is $14,047 \mathrm{~m} 2-23,412 \mathrm{~m} 2$.

\section{2) Demand of storage scale of manufacturing enterprises}

a) Analysis on the demand of storage scale of the general manufacturing enterprise (including coal machine)

A survey of manufacturing enterprise found that most middle and small-sized enterprises do not have obvious requirements for warehousing outsourcing due to the fact that the annual logistics quantity is not particularly large, plus they are generally based on their own warehouse. However, for enterprises with relatively large logistics scale, such as Fangrui, it has a surplus in its own storage capacity. Therefore, if the traditional warehousing service mode is concerned, the demand for the storage service of the manufacturing enterprise is not obvious.

However, many enterprises have expressed a strong interest in logistics finance, so we must take logistics financial services as the entry point to effectively stimulate warehousing requirement. The following analysis of the demand for storage scale is exactly based on the foundation of logistics finance.

Based on the data from the previous analysis, the annual freight volume that the manufacturing enterprises have the demand of warehousing service in this logistics is 874,400 tons Calculated by 10 times of annual turnover rate, the average stock is 87,440 tons, which have a demand of warehousing scale: $\mathrm{W}=\mathrm{q} /(\mathrm{P} * \mathrm{~K})$

$$
=87440 /(1 * 0.7)=124914 \mathrm{~m} 2
$$

$\mathrm{W}=\mathrm{q} /(\mathrm{P} * \mathrm{~K})$

$=87440 /(1 * 0.7)=124914 \mathrm{~m} 2$

In the formula:

$\mathrm{W}$ - storage area, $\mathrm{m} 2$;

$\mathrm{q}$ - Goods stock, ton;

$\mathrm{P}$-Material storage capacity in effective area of per square meter; comprehensively considering the different attributes of various goods, this logistics center roughly determines that its storage capacity per square meter is 1 ton;

$\mathrm{K}$ - utilization rate of warehouse floor space; this logistics center has initially determined its utilization rate to be 0.7 .

Assuming that this logistics center can seize 30\%-50\% market share of manufacturing enterprises, its storage scale requirement is $37,474 \mathrm{~m} 2-62,457 \mathrm{~m} 2$.

b) Analysis on the demand of storage scale of agricultural machinery enterprises

Among the surveyed agricultural machinery companies, the total demand of the storage scale for the two agricultural machinery enterprises is $9,000 \mathrm{~m} 2$. According to the market 
share of the two agricultural machinery enterprises, it can be estimated that the storage scale requirements of agricultural machinery enterprises should be at least $20,000 \mathrm{~m} 2$ or more.

Assuming that this logistics center can seize 30\%-50\% market share of agricultural machinery enterprises, its storage scale requirement is $6,000 \mathrm{~m} 2-10,000 \mathrm{~m} 2$.

\section{3) Summary}

The following conclusions are initially drawn on the basis of the analysis on the existing surveys:

The storage requirements associated with the project operation in this area can be divided into two major parts, namely, commercial circulation industry and manufacturing enterprise. The commercial circulation industry shows a greater demand in market, while the storage requirement of manufacturing enterprise depends on logistics finance to pull.

The total demand on storage scale associated with project operation in this area is about 200 thousand $\mathrm{m} 2$.

Preliminarily assuming that the market share of storage requirement is $30 \%-50 \%$ in this project, its requirement of storage scale is $60,000 \mathrm{~m} 2-100,000 \mathrm{~m} 2$.

\section{B. Market Demand Analysis of Logistics Less-Than-Carload Freight}

LD has a great demand for logistics LCL market, mainly reflected in the following aspects:

The commercial circulation enterprises and manufacturing enterprises in the survey have showed extreme dissatisfaction with the current road logistics LCL market that is dispersed, small, chaotic and poor. They urgently hope that LD City has a large-scale LCL market with standardized management and complete line;

Many small and medium-sized logistics LTL enterprises are also dissatisfied with the current situation. They hope that there will a better LTL market for them to engage in where the agglomeration effect can be formed, and the enterprises can make bigger and stronger in the LD LTL market;

With the aid of the road LTL market, the inherent advantages of the railway can be exerted to help them realize the door-to-door service.

Combined with the development trend of LTL market demand in LD, referring to the scale of LTL market in Changsha and Shaoyang, it is initially estimated that more than 100 LCL enterprises will be required to settle in this logistics center to form its agglomeration and scale advantages. According to the calculation that every LCL enterprise covers an area of about $60 \mathrm{~m} 2$ on average, the LTL market requires $6,000 \mathrm{~m} 2$ of building area.

\section{Demand Analysis of Steel Trading Exhibition Area}

22 steel trading enterprises that have been sampled put forward clear requirements for their steel trading exhibition area. According to the calculation that every merchant needs $60 \mathrm{~m} 2$ of trading exhibition area, 80 steel trading enterprises need a total area of $48,000 \mathrm{~m} 2$ of steel die trading exhibition area.

\section{Demand Analysis of Goods Parking Lot}

Currently, there is no standardized, larger-scale goods parking lot in LD City, which is one of the main reasons that limit the relatively backward development of the local LCL market. Therefore, the logistics center urgently needs to be built a large-scale parking lot to meet the matching demand. Its scale is designed based on accommodating 100 large vehicles, with a floor area of about $30,000 \mathrm{~m} 2$.

\section{POSITIONING ANALYSIS OF THE CONSTRUCTION OF MULTIMODAL TRANSPORT CENTER}

\section{A. Background Analysis}

The government planning of LD City has defined: Wanbao New District shall be a logistics park for consumer goods, mainly selling consumer goods and daily necessities, while the development area shall be a production data logistics park. LD City is located at the development area, and there are many manufacturing companies around, with well-developed traffic.

The manufacturing industry in LD City is relatively prosperous. From the geographical position, manufacturing industry and industrial logistics centers have a wide range of radiation, which can directly reach the big cities in China and even the Southeast Asia. Moreover, the industry has a good development trend and an optimistic market prospect. To integrally plan the logistics market of the manufacturing industry, we can scientifically arrange and establish a large

\section{B. Target Positioning}

It is suggested that the multimodal transport center should be constructed starting from the manufacturing industry. An appropriate vacancy will be left to meet the requirements of new things. Or when the concept is increased, there will be a certain position in the system rather than the classification system being pushed and started again due to the increase of new things or concepts. Meanwhile, we should also create conditions for the extension and refinement of other functions based on the system constructed by it.

\section{Enterprise Positioning}

First of all, this project will focus on a class of services to avoid a large and complete, and scattered condition. Using differentiated services meets the needs of specific market (for example, the needs of manufacturing industry) to avoid the homogeneous competition. We will strive to become a professional multimodal transport operation management company with efficient, convenient, safe, and standardized logistics in LD City.

\section{CONSTRUCTION CONTENT OF MULTIMODAL TRANSPORT CENTER}

The multimodal transport logistics center project will be built into a national-level regional logistics hub center which provides the specialized logistics enterprises, industrial enterprises and commercial enterprises with logistics operation facilities and integration environment. This project is based on the "steel industry chain", serves the $3+5$ urban agglomeration, and radiates the South Central China. 
Based on the development conception and market positioning of multimodal logistics center, this project will build the large scale logistics infrastructure platform, large scale e-commerce and logistics information service platform, logistics trading platform, logistics enterprise headquarters platform, logistics value-added service platform and so on. The specific contents of the project construction include the integrated office service area, multimodal transport service area, business transaction and display service area, ecommerce and logistics information service area, storage service area, life supporting service area, and other management rooms and supporting facilities.

\section{A. Integrated Office Service Area}

This area will build one logistics headquarters building and one integrated office service building, and provide the services such as business management, logistics finance, administration, logistics settlement and so on. This area has a total floor area of 42574.84 square meters.

\section{B. Multimodal Transport Service Area}

This area is an exclusive area providing services for multimodal transport, and equipped with two special lines for railway. The temporary storage, transfer and simple processing storage area for multimodal transport goods is also built in this area, with a total area of 30,000 square meters.

\section{Commercial and LTL Logistics Transaction Service Area}

This area constructs the trading and LTL logistics transaction service area, with a total floor area (floor 1-3) of 55219.5 square meters. Among it, the commercial transaction service area is arranged along the intersection of Qiupu Street and Yingchun Road, with a floor area (floor 1-3) of 38653.65 square meters, and the LTL logistics transaction service area is arranged along the intersection of Qiupu Street and Jianglong Road, with a floor area (floor 1-3) of 16565.85 square meters.

\section{E-Commerce and Logistics Information Service Area}

This area constructs e-commerce service center, logistics information service center, logistics information transaction hall, freight information loading center and so on, with a total floor area of 5,000 square meters. This area is arranged inside the integrated office service area.

\section{E. Storage and Lean Distribution Service Area}

This area mainly consists of free warehouse, storehouse, and distribution center and so on. It mainly provides storage service and distribution service. The floor area of general cargo and multimodal transport distribution storage area is 4,278 square meters and 50,000 square meters respectively (the storage area is planned to be constructed in the plot $\mathrm{K}$ of east of Yingchun Road, or to be carried out adding story construction on the existing turnover storage area). One lean ecommerce distribution center building is built in this area, with the floor area of 4543.64 square meters. The floor area of storehouse (floor 4-6 of the commercial and LTL logistics transaction service area) is 55219.5 square meters.

\section{F. Multimodal Transport Capacity Allocation Area}

This area constructs the multimodal transport power allocation area, and the dropping and pulling center and power allocation center cover an area of 50,000 square meters.

\section{RESEARCH ON OPERATION AND MANAGEMENT Mode OF MULTIMODAL TRANSPORTATION CENTER}

The business mode of traditional logistics park should be changed: first of all, we should make an enclosure plan in the name of logistics, and then attract investment. After building the warehouses and facades, sell the facades and rent out the warehouses to carry out various businesses and gain small profits instead of continuous development. The business mode shall be changed as the strategic cooperative partnership with large-scale manufacturing enterprises led by the government, and it can utilize the original influence and channel of manufacturing enterprises to integrate the relative logistics resources about manufacturing after alignment, so as to attract logistics enterprise to enter in.

\section{A. Obstacles to the Construction of Strategic Partnerships}

The proportion of self-run logistics of manufacturing enterprise is relatively high; for example, LY Steel has more than 305 self-owned transport vehicles, and its partner, Hongtong, has 95 sets.

The manufacturing enterprises worry about outsourcing failures: in LD City, there are almost no third-party logistics companies specializing in serving large enterprises. Very few third-party logistics companies specialize in serving small and medium-sized enterprises, and their problems, such as low operation speed, lack of networked logistics services and high operating costs, are very serious. It is even more difficult to meet the urgently needed value-added services and integrated services.

The products of manufacturing enterprise are complex, and they need a customized solution. However, the logistics enterprises do not understand the process design of manufacturing and supply chain, and naturally cannot effectively participate in the management of supply chain.

The logistics facilities and informationalized level in the logistics enterprise are not enough. The survey found that: the main reasons for the dissatisfaction of the manufacturing enterprises with the three party logistics are the lack of timeliness and accuracy of logistics information and slow operation speed.

\section{B. Suggestions on the Strategy of Operation and Management Mode of Multimodal Transport Center}

Due to the low level of logistics services and management in the whole LD City and the lack of standardized and unified logistics operations and standards, the concept of quality management should be introduced when planning the park. Quality management belongs to any activity that sets the quality plan and completes the plan. The introduction of quality management in the park is to use the information support quality. We should conduct the quality management in many aspects such as equipment introduction, personnel 
service management, standardization construction and so on. We must use lean management, PDCA and CQQ to cooperate with the construction of the logistics park, and continue to improve.

Because of the backward logistics facilities and extreme low informationalized level of third-party enterprises, it is suggested that the information platform should be started in advance in the planning and construction of the entire project. The personalized needs cannot be met due to the lack of rapid information response and modern logistics facilities. After the platform is built, a new model can be developed in cooperation with logistics companies, and the government will assist in promotion to increase credibility.

Due to the complex and troublesome connection process of logistics industry and manufacturing industry, it is suggested that more professional logistics personnel should be absorbed and trained. Moreover, it should establish specialized logistics service group for these people who understand the manufacturing industry participate in the project construction. At present, the prominent contradictions between logistics industry and manufacturing industry are: the logistics enterprises do not understand the actual demands of manufacturing enterprises, as well as the features of operation pattern and manufacturing technique, post setting, process and link and so on, therefore, they cannot effectively participate in the supply chain of manufacturing enterprises; the manufacturing enterprises do not rely upon the provisioning service ability of logistics enterprises and dare not outsource their business. Based on the above contradictions, first of all, it should send far and wide to invite men of ability and provide with one-stop reception service for the manufacturing enterprises by their specialized image and management.

A good mechanism to communicate with the government needs to be built.

To achieve the above strategic positioning, it is suggested that the park should focus on constructing the three major platforms:

\section{- Socialization logistics information platform}

Socialization logistics information platform applies to information approach to integrate the information of freight source from industrial and commercial enterprises and information of car source from small and medium-sized logistics enterprises, social vehicle and individual freight forwarding, and introduce the logistics matched service resources of tax administration, so as to shorten the allocation time of cargo, improve the allocation efficiency and reduce the logistics cost.

\section{- Manufacturing industry logistics linkage platform}

Manufacturing industry logistics linkage platform aims to achieve the interactive development of manufacturing industry and logistics industry, promote the cooperation of large-scale industrial enterprise and specialized Third-party Logistics Service Provider, reduce the operating cost and improve the efficiency of logistic development of manufacture enterprises, and help the logistics enterprise to enhance logistic service ability and adapt to the development demand of manufacturing industry.

\section{- One-stop integrated service platform}

One-stop integrated service platform: it needs to introduce the logistics service platform operator who can provide the equipment and facilities, information support, operation matched service and other series of integrated services for the logistics enterprises in this park, and offer the good development environment for the enterprises, and promote the standard operation and rapid development of the park.

\section{CONCLUSION}

The construction of multimodal transport center in LD is the typical project of traditional railway freight depot transformation and upgrading of central region of China and will provide some references, to some extent, for the modern transformation of railway freight depot in other regions with demand analysis, positioning, construction content and operation model.

\section{REFERENCES}

[1] Hao Panfeng. Research on the Construction of Railway Logistics Cente and Multimodal Transport Hub Logistics Park[J]. New Silk Road Horizon. 01, 2016: 54-55.

[2] Yang Leru. The Future Continuous Tense of Multimodal Transport?[J]. Logistics and Material Handing (goods stock). 2010(03):16-18

[3] Yan Huaqiang. The Development Status and Countermeasure Analysis of Xiangyang Multimodal Transport[J]. Logistics Technology. 2017(08) $51-53+100$

[4] Wang Ming. The Status and Development Tendency of China's Multimodal Transport[J]. China Logistics and Purchasing. 2016(23): 92-94 